Article

\title{
Effects of the Appropriate Addition of Antioxidants from Pinus densiflora and Mentha canadensis Extracts on Methane Emission and Rumen Fermentation
}

\author{
Shin Ja Lee ${ }^{1,+}+$, , Ye Jun Lee ${ }^{2,+}$, Jun Sik Eom ${ }^{2}$, Hyun Sang Kim ${ }^{2}$, You Young Choi ${ }^{2}$, \\ Seong Uk Jo ${ }^{2}$, Suk Nam Kang ${ }^{3}$, Ha Young Park ${ }^{4}$, Do Hyung Kim ${ }^{5}$ and Sung Sill Lee ${ }^{1,2, * \mathbb{C}}$ \\ 1 Institute of Agriculture and Life Science \& University-Centered Labs, Gyeongsang National University, \\ Gyeongsangnam-do, Jinju-si 52828, Korea; tlswk1000@hanmail.net \\ 2 Division of Applied Life Science (BK21Plus), Gyeongsang National University, Gyeongsangnam-do, \\ Jinju-si 52828, Korea; yejun0215@gmail.com (Y.J.L.); skyandstar07@naver.com (J.S.E.); \\ 2437401@naver.com (H.S.K.); dudolboy301@naver.com (Y.Y.C.); jsu9412@naver.com (S.U.J.) \\ 3 Department of Animal Resource, Daegu University, Gyeongbuk 38453, Korea; whitenightt@hanmail.net \\ 4 Department of Pathology, Busan Paik Hospital, Inje University College of Medicine, Busan 47392, Korea; \\ hy08.park@gmail.com \\ 5 Department of Animal Science, Gyeongbuk Provincial College, Yecheon 36830, Korea; dh.kim@korea.kr \\ * Correspondence: lss@gnu.ac.kr; Tel.: +82-055-772-1883; Fax: +82-055-772-1889 \\ + These authors contributed equally to this work.
}

Received: 14 September 2020; Accepted: 14 October 2020; Published: 15 October 2020

Simple Summary: In the livestock industry, increasing attention is being focused on ways to reduce artificial greenhouse gas emissions from ruminants or provide alternatives to homeostasis. Pinus densiflora and Mentha canadensis extracts, with antioxidant properties, inhibit methanogenesis in ruminants and improve both digestion and growth of animals. Long-term stability of these plant extracts provides further support for their use as a substitute for other rumen regulators. It is expected that new additives for ruminants will be developed from P. densiflora and M. canadensis extracts, which are composed of phenolic compounds for improving the growth and immunity of ruminants.

\begin{abstract}
This study aimed to investigate the optimal addition of terpene-based Pinus densiflora and Mentha canadensis extracts, with antioxidant and methane reduction effects, as feed supplements to ruminants. Two cannulated steers $(450 \pm 30 \mathrm{~kg})$, consuming Timothy Hay and a commercial concentrate $(60: 40, w / w)$ twice daily (at 09:00 and 17:30) at 2\% of body weight, with free access to water and a mineral block, were used as rumen fluid donors. In vitro fermentation experiments, with Timothy Hay as the substrate, were conducted with $P$. densiflora and $M$. canadensis extracts as supplements to achieve concentrations of 30,50 , and $70 \mathrm{mg} / \mathrm{L}$ on a Timothy Hay basis. Fibrobacter succinogenes decreased in proportion upon $P$. densiflora and $M$. canadensis extract supplementation at $50 \mathrm{mg} / \mathrm{L}$, while the dry matter degradability of the feed was not significantly different $(p<0.05)$. Methane emission was significantly lower in the 50 and $70 \mathrm{mg} / \mathrm{L}$ treatment groups, for both extracts, at $12 \mathrm{~h}(p<0.05)$. Based on methane production and antioxidant activity, our study suggests that $30 \mathrm{mg} / \mathrm{L}$ addition is the most appropriate level of supplementation.
\end{abstract}

Keywords: Pinus densiflora; Mentha canadensis; methane emission; feed supplementation; ruminants

\section{Introduction}

Methane produced from enteric fermentation in the livestock industry contributes approximately $20 \%$ of total global methane emissions [1]. Ruminal methanogenesis is an essential metabolic process 
that functions to maintain steady state fermentation, as it plays a vital role in scavenging the molecular hydrogen generated during fermentation. Methane is a natural by-product of ruminant digestion that serves as a hydrogen sink. However, given that methanogenesis is influenced by rumen microbial activity, the production of methane is dependent to varying extents upon animal species, age, and management, and, primarily, by the quality and quantity of feedstuffs administered to animals [2].

In the livestock industry, the market for feed additives is rapidly changing, with increasing attention being paid to ways of reducing artificial greenhouse gas emissions from ruminants or providing alternatives to homeostasis. Recently, several polysaccharides and plant extracts have been reported to show a prebiotic effect [3]. In China, various natural plants and extracts are used as animal feed additives for antimicrobial purposes, strengthening immunity, and reducing stress [4].

The components of Pinus densiflora and Mentha canadensis differ depending on region, climate, and other geographical and environmental features. P. densiflora is a needle-leaf tree distributed across eastern Asia. In recent years, pine needles have been reported to have antioxidant, antibacterial, anti-inflammatory, antimutagenic, and anti-tumor activities [5-8]. Several chemical compositions of pine needles have been identified to date [9]. P. densiflora is composed of $21.55 \% \alpha$-pinene, $6.36 \%$ camphene, 9.32\% $\beta$-pinene, $0.46 \%$ myrcene, $13.05 \%$ limonene, $8.39 \%$ terpinolene, $1.07 \% \alpha$-terpineol, and $5.01 \%$ bornyl acetate [10]. The essential oils of $P$. densiflora have mild anti-microbial properties and can inhibit the growth of both Gram-positive and Gram-negative bacteria, as well as fungi [11]. Pine oil contains 58-97\% $\beta$-ocimeneyne; almost all other components, such as piperitone (11.74\%), camphene $(7.20 \%)$, and $\beta$-pinene $(5.64 \%)$, have been identified as monoterpene components. The ester component, endobornyl acetate, was analyzed to be present at approximately 5.63\% [12].

M. canadensis is distributed all over the world and can be found in many environments. M. species, one of the world's oldest and most popular herbs, and it is widely used in cooking and as an alternative or complementary therapy, mainly for the treatment of gastrointestinal disorders, such as flatulence, indigestion, nausea, vomiting, anorexia, and ulcerative colitis. The essential oils and extracts of M. species are documented to possess antimicrobial, fungicidal, antiviral, insecticidal, and antioxidant properties [13]. The main components of $M$. species are carbon $(40.8 \pm 1.23 \%)$ and limonene $(20.8 \pm$ $1.12 \%)$, followed by 1,8 -cineole $(17.0 \pm 0.60 \%), \beta$-pinene $(2.2 \pm 0.25 \%)$, cis-dihydrocarbon $(1.9 \pm 0.49 \%)$, dihydrocarveol $(1.7 \pm 0.31 \%)$, and $\alpha$-pinene $(1.4 \pm 0.17 \%)$ [14]

Natural extracts of $P$. densiflora and $M$. canadensis are known to contain terpenoid substances, and extracts containing phenol and flavonoids are expected to be effective with respect to rumen fermentation and methane reduction. We aimed to verify the effect of these extracts on rumen fermentation. Furthermore, we evaluated their antibacterial and methane-reducing effects depending on the level of addition. Extracts from P. densiflora and M. canadensis were further evaluated for optimizing the amount to be added as a supplement in the ruminants' functional feed.

\section{Materials and Methods}

\subsection{Ethics Statement}

All experimental procedures involving animals were approved by the Animal Ethics Committee of Gyeongsang National University (Gyeongsangnam-do, Jinju, Korea; GNU-180130-A0007).

\subsection{In Vitro Batch Fermentation}

Two Hanwoo steers $(450 \pm 30 \mathrm{~kg})$, each fitted with a ruminal cannula, were used. Steers were offered free access to water and were fed $600 \mathrm{~g} / \mathrm{kg}$ timothy and, $400 \mathrm{~g} / \mathrm{kg}$ cracked corn-based concentrate (crude protein, $120 \mathrm{~g} / \mathrm{kg}$; ether extracts, $15 \mathrm{~g} / \mathrm{kg}$; crude fiber, $150 \mathrm{~g} / \mathrm{kg}$; crude ash, $120 \mathrm{~g} / \mathrm{kg}$; Ca, $7.5 \mathrm{~g} / \mathrm{kg}$; P, $9.0 \mathrm{~g} / \mathrm{kg}$; total digestible nutrients, $690 \mathrm{~g} / \mathrm{kg}$ dry matter (DM) basis). The diet was fed to supply at $3 \%$ of BW in two equal portions at 07:00 and $1700 \mathrm{~h}$ daily, and intake adaptation periods were for a minimum of 14 days. 
In vitro fermentation was conducted following the procedure described by Kim et al. [15]. Approximately $2 \mathrm{~kg}$ of ruminal fluid were collected from two ruminal cannulated steer $2 \mathrm{~h}$ after the morning feeding and were processed with a Waring blender under a $\mathrm{CO}_{2}$ atmosphere and filtered through four layers of cheesecloth and glass wool prior to combining with McDougall buffer [16]. The McDougall buffer and ruminal inoculums were combined to a 2:1 ratio, and this mixture was then added to fermentation vessels containing 0 or $300 \mathrm{mg}$ (based on DM) of timothy as a substrate. Pinus densiflora and Mentha canadensis extracts for treatments were purchased from the Plant Extract Bank of Korea Research Institute of Bioscience and Biotechnology (Daejeon, Korea) and used in experiments. Prepared extracts of the $100 \mathrm{mg} / \mathrm{mL}$ stock solution used for treatments were diluted to 30, 50, and $70 \mathrm{mg} / \mathrm{L}$ with DMSO (Dimethyl sulfoxide, Sigma-Aldrich Chemical Co., St. Louis, MO, USA) through stepwise dilution.

The experimental design was completely randomized and conducted in duplicate and replicated on three separate days ( $n=3$ for statistical analyses). Gas production was monitored after 3, 6, 9, 12, 24, 48 , and $72 \mathrm{~h}$ of incubation at $39^{\circ} \mathrm{C}$.

\subsection{Total Phenolic and Flavonoid Content of Pinus densiflora and Mentha canadensis Extracts}

Total phenolic content was determined with the Folin-Ciocalteu reagent according to the procedure described by Singleton and Rossi [17]. Briefly, Gallic acid was used as a reference standard calibration curve, and the results were expressed as milligram gallic acid equivalent (mg GAE)/g dry weight (g DW).

Total flavonoid content was determined using the method of Meda et al. [18] with minor modifications. Quercetin was used a standard calibration curve to quantify the total flavonoid content. Results were expressed in milligram quercetin equivalents (mg QE)/g dry weight (g DW).

The detailed procedures of such radical analyses were the same as those of Kang et al. [19].

\subsection{Total DPPH, ABTS and HO, NO Radical Assay}

The DPPH (2,2-Diphenyl-1-picrylhydrazyl) radical activity analysis was performed according to Kang et al. [19] method by modifying the method of Brand-Williams [20]. The free radical activity of samples 0.05 to $1 \mathrm{mg} / \mathrm{mL}$ in DMSO was measured. L-ascorbic acid was used as a standard. The absorbance was measured by a spectrophotometer (Ultrospec 2100 pro, Amersham Pharmacia Biotech Co., Piscataway, NJ, USA) at $517 \mathrm{~nm}$.

The ABTS $\left\{2,2^{\prime}\right.$-Azino-bis(3-ethylbenzothiazoline-6-sulphonic acid) $\}$ radical activity analysis was conducted using the method indicated by Re et al. [21]. Briefly, $2.85 \mathrm{~mL}$ of this ABTS+ solution was added to $0.15 \mathrm{~mL}$ of different concentrations of the samples, and the decrease in absorbance at $734 \mathrm{~nm}$ was observed after mixing for up to $10 \mathrm{~min}$.

Hydroxyl $(\mathrm{HO})$ radical scavenging activity of different concentrations of MEPA (P. densiflora and M. Canadensis extracts) was determined by the method of Elizabeth et al. [22]. The mixture's absorbance was measured at $532 \mathrm{~nm}$ against an appropriate blank solution. BHA and Catechin was used as a reference compound. The results were compared with BHA and Catechin.

The Nitric oxide (NO) radical inhibition was estimated by the Griess Ilosvay reaction according to Hyoung [23] with slight modifications. Briefly, the absorbance was measured at $546 \mathrm{~nm}$. Butylated hydroxyanisole was used as a standard.

The percent inhibition was calculated using the following formula: $\%$ inhibition $=(\mathrm{A} 0-\mathrm{A} 1) / \mathrm{A} 0 \times 100$.

In the formula, A0 is the absorbance of the control, and A1 is the absorbance of the sample and standard compound.

\subsection{Analysis of In Vitro End-Products}

At the end of each incubation time, the fermentation vessels were placed in an ice bath to measure the headspace gas pressure in each vessel using a digital readout voltmeter (Laurel Electronics, Inc., Costa Mesa, CA, USA). Gas samples for $\mathrm{CH}_{4}$ and $\mathrm{CO}_{2}$ analysis were transferred into a vacuum test tube 
(Vacutainer, Becton Dickinson, Franklin Lakes, NJ, USA) and analyzed by gas chromatography (Agilent Technologies HP 5890; Santa Clara, CA) using a TCD detector with a Column Carboxen 1006PLOT capillary column $30 \mathrm{~m} \times 0.53 \mathrm{~mm}$ (Supelco), following the procedure described in Kim et al. [15]. A standard mixture of $\mathrm{CH}_{4}$ and $\mathrm{CO}_{2}$ (RIGAS, Daejeon, Korea) was used to determine the $\mathrm{CH}_{4}$ concentrations of samples. Vacuum tubes containing gas samples under refrigeration were warmed prior to gas analysis by allowing the tubes to equilibrate in a gas chromotograph (Agilent Technologies HP 5890; Santa Clara, CA, USA) for at least $30 \mathrm{~min}$.

The amount of microbial growth rate was determined as optical density (OD) value at $550 \mathrm{~nm}$ with a spectrophotometer (Model 680, Bio-Rad Laboratories, Hercules, CA, USA). For measuring glucose, $200 \mu \mathrm{L}$ of supernatant was mixed with $600 \mu \mathrm{L}$ of DNS solution and incubated for 5 min in a boiling water bath. Glucose concentration was the OD at $595 \mathrm{~nm}$, determined with a microplate reader (Model 680, Bio-Rad Laboratories, Irvine, CA, USA) [24].

\subsection{Relative Quantification of Specific Ruminal Microbes}

Quantitative real-time polymerase chain reaction was carried out in the same way as the papers of Lee et al. [24] and Lee at al. [25], Polymerase chain reaction (PCR) primer sets were then used in this study to detect and amplify DNA from Fibrobacter succinogenes (forward primer: GTT CGG AAT TAC TGG GCG TAA A; reverse primer: CGC CTG CCC CTG AAC TAT C), Ruminococcus flavefaciens (forward primer: CGA ACG GAG ATA ATT TGA GTT TAC TTA GG, reverse primer: CGG TCT CTG TAT GTT ATG AGG TAT TAC C), and Ruminococcus albus (forward primer: CCC TAA AAG CAG TCT TAG TTC G; reverse primer: CCT CCT TGC GGT TAG AAC A), and the primers used were the same as those referenced by Denman and McSweeney [26], Koike and Kobayashi [27], and Skillman et al. [28], respectively. A total bacteria primer set (forward: CGG CAA CGA GCG CAA CCC; reverse: CCA TTG TAG CAC GTG TGT AGC C) was used as the internal standard [25]. Ciliate-associated methanogens primer set (forward primer: AGG AAT TGG CGG GGG AGC AC; reverse primer: TGT GTG CAA GGA GCA GGG AC) was the same as those referenced by Luton et al. [29].

\subsection{Statistical Analysis}

Obtained data were analyzed using the general linear model procedure of SAS (version 9.2, SAS Inst. Inc., Cary, NC, USA) for a completely random design including terms for dosing levels, time, and their interaction. Duncan's multiple range test was used to interpret any significant differences among the means values of doing levels for estimating the most appropriate level of supplementation. Orthogonal contrast was used to assess linear and quadratic relationships between the dosing levels of herb and pine and the dependent variables. Orthogonal coefficients for unequally spaced dosing levels were acquired using the IML procedure (SAS Inst. Inc., Greenwood Village, CO, USA). Means were considered significantly different if $p \leq 0.05$ [30].

\section{Results}

\subsection{Total Phenol and Flavonoid Contents, DPPH and ABTS Assays, OH and NO Scavenging Activities}

The total phenol content in P. densiflora extracts was $925 \pm 113.24 \mu \mathrm{g} / \mathrm{g}$ and that in M. canadensis extracts was $469 \pm 14.27 \mu \mathrm{g} / \mathrm{g}$. The total flavonoid content was $680.90 \pm 67.49$ and $715.77 \pm 61.01 \mu \mathrm{g} / \mathrm{g}$, respectively. DPPH was $49.38 \pm 2.54$ and $48.25 \pm 1.28$ at the concentration of $200 \mu \mathrm{g} / \mathrm{mL}$, respectively, whereas ABTS was $78.85 \pm 0.98$ and $91.36 \pm 0.29$ at the concentration of $200 \mu \mathrm{g} / \mathrm{mL}$, respectively.

The hydroxyl radical $(\mathrm{OH})$-scavenging activity of $P$. densiflora extract at concentrations of 200, 100,50 , and $10 \mu \mathrm{g} / \mathrm{mL}$ was $336.36 \pm 100.39,2251.17 \pm 137.16,1707.47 \pm 115.93$, and $790.53 \pm 50.97$, respectively. The nitric oxide (NO)-scavenging activity of $M$. canadensis extract at concentrations of $200,100,50$, and $10 \mu \mathrm{g} / \mathrm{mL}$ was $54.93 \pm 2.92,32.50 \pm 2.52,20.35 \pm 3.71$, and $12.04 \pm 3.74$, respectively (Table 1). 
Table 1. Antioxidant capacities (DPPH, ABTS, HO) and nitric oxide (NO) inhibition of Pinus densiflora and Mentha canadensis plant extracts.

\begin{tabular}{|c|c|c|}
\hline \multirow{2}{*}{ Content } & \multicolumn{2}{|c|}{ Terpene-Based Plant Extract } \\
\hline & Pinus densiflora & Mentha canadensis \\
\hline Total polyphenol content ( $\mu \mathrm{g}$ GAE/g) & $925 \pm 113.24$ & $469 \pm 14.27$ \\
\hline Total flavonoid content $(\mu \mathrm{g} Q E / g)$ & $680.90 \pm 67.49$ & $715.77 \pm 61.01$ \\
\hline \multicolumn{3}{|c|}{ Total antioxidant capacity } \\
\hline \multicolumn{3}{|c|}{ DPPH } \\
\hline $200(\mu \mathrm{g} / \mathrm{mL})$ & $49.38 \pm 2.54$ & $48.25 \pm 1.28$ \\
\hline $100(\mu \mathrm{g} / \mathrm{mL})$ & $43.27 \pm 2.66$ & $47.56 \pm 1.63$ \\
\hline $50(\mu \mathrm{g} / \mathrm{mL})$ & $21.90 \pm 1.09$ & $37.95 \pm 4.63$ \\
\hline $10(\mu \mathrm{g} / \mathrm{mL})$ & $16.63 \pm 3.39$ & $17.38 \pm 1.53$ \\
\hline \multicolumn{3}{|c|}{ ABTS } \\
\hline $200(\mu \mathrm{g} / \mathrm{mL})$ & $78.85 \pm 0.98$ & $91.36 \pm 0.29$ \\
\hline $100(\mu \mathrm{g} / \mathrm{mL})$ & $67.34 \pm 0.85$ & $90.51 \pm 0.68$ \\
\hline $50(\mu \mathrm{g} / \mathrm{mL})$ & $52.20 \pm 3.41$ & $82.68 \pm 1.20$ \\
\hline $10(\mu \mathrm{g} / \mathrm{mL})$ & $23.11 \pm 1.16$ & $79.50 \pm 1.97$ \\
\hline \multicolumn{3}{|c|}{$\mathrm{HO}$} \\
\hline $200(\mu \mathrm{g} / \mathrm{mL})$ & $2336.36 \pm 100.39$ & $299.97 \pm 43.00$ \\
\hline $100(\mu \mathrm{g} / \mathrm{mL})$ & $2251.17 \pm 137.16$ & $179.81 \pm 30.84$ \\
\hline $50(\mu \mathrm{g} / \mathrm{mL})$ & $1707.47 \pm 115.93$ & $102.46 \pm 7.81$ \\
\hline $10(\mu \mathrm{g} / \mathrm{mL})$ & $790.53 \pm 50.97$ & $37.11 \pm 6.80$ \\
\hline \multicolumn{3}{|c|}{$\mathrm{NO}$} \\
\hline $200(\mu \mathrm{g} / \mathrm{mL})$ & $59.31 \pm 1.36$ & $54.93 \pm 2.92$ \\
\hline $100(\mu \mathrm{g} / \mathrm{mL})$ & $32.42 \pm 2.01$ & $32.50 \pm 2.52$ \\
\hline $50(\mu \mathrm{g} / \mathrm{mL})$ & $20.59 \pm 3.14$ & $20.35 \pm 3.71$ \\
\hline $10(\mu \mathrm{g} / \mathrm{mL})$ & $7.94 \pm 2.59$ & $12.04 \pm 3.74$ \\
\hline
\end{tabular}

DPPH: 2,2-Diphenyl-1-picrylhydrazyl radical scavenging activity; ABTS: 2,2'-Azino-bis(3-ethylbenzothiazoline6-sulphonic acid) radical scavenging activity; HO: Hydroxyl radical scavenging activity; NO: Nitric oxide (NO) inhibition; GAE: gallic acid equivalent; QE: quercentin equivalent.

\subsection{Effect of Terpene-Based Plant Extracts on Rumen Fermentation and Dry Matter Degradability}

The $\mathrm{pH}$ of $P$. densiflora and M. canadensis extracts was maintained in the range of 6.56-6.82 and 6.24-6.62, respectively. Among the treatments, the $50 \mathrm{mg} / \mathrm{L}$ treatment presented the lowest values $(p<0.05)$ at 6.48 and 6.69 , respectively (herb: treatments effect, $p=0.0003$, quadratic effect, $p=0.0099$; pine: treatments effect, $p=0.0055$, quadratic effect, $p=0.0338$ ). Incubation for $12 \mathrm{~h}$ and $24 \mathrm{~h}$ showed a significant difference only in the $50 \mathrm{mg} / \mathrm{L}$ addition treatment $(p<0.05)$. Furthermore, the results of microbial growth had no adverse effect throughout the fermentation time. At $12 \mathrm{~h}$, microbial growth was significantly lower $(p<0.05)$ than the control at $M$. canadensis $30 \mathrm{mg} / \mathrm{L}$ addition treatments. At $24 \mathrm{~h}$, microbial growth was significantly lower $(p<0.05)$ than the control at $M$. canadensis $70 \mathrm{mg} / \mathrm{L}$ addition treatments. Glucose concentration was significantly lower than other treatments at $M$. canadensis $50 \mathrm{mg} / \mathrm{L}$ addition treatments after $12 \mathrm{~h}$ of incubation (treatments effect, $p=0.0244$; quadratic effect, $p=0.0086$ ). After $24 \mathrm{~h}$, the control and $M$. canadensis $50 \mathrm{mg} / \mathrm{L}$ addition treatments were lower than the other treatments (treatments effect, $p=0.0242$; quadratic effect, $p=0.0446$ ). Protein concentration decreased by $70 \mathrm{mg} / \mathrm{L}$ of $M$. canadensis extract following $12 \mathrm{~h}$ (linear effect, $p=0.0273$ ). The ammonia-nitrogen concentration changed linearly $(p=0.0273)$ following $12 \mathrm{~h}$ of incubation; this was decreased by $50 \mathrm{mg} / \mathrm{L}$ M. canadensis treatment after $12 \mathrm{~h}$ of incubation (Table 2). 
Table 2. Effects of terpene-based plant extracts on ruminal fermentation characteristics after 12 and $24 \mathrm{~h}$ of in vitro incubation.

\begin{tabular}{|c|c|c|c|c|c|c|c|c|c|}
\hline \multirow{2}{*}{ Incubation Time (h) } & \multirow{2}{*}{ Treatment } & \multicolumn{4}{|c|}{ Extract Concentration $^{(1)}(\mathrm{mg} / \mathrm{L})$} & \multirow{2}{*}{ SEM $^{(2)}$} & \multicolumn{3}{|c|}{$p$ Value $^{(3)}$} \\
\hline & & 0 & 30 & 50 & 70 & & $\mathrm{~T}$ & $\mathbf{L}$ & $Q$ \\
\hline \multicolumn{10}{|c|}{$\mathrm{pH}$} \\
\hline \multirow{2}{*}{12} & Herb ${ }^{(4)}$ & $6.58^{\mathrm{a}}$ & $6.60^{\mathrm{a}}$ & $6.48^{\mathrm{b}}$ & $6.62^{\mathrm{a}}$ & 0.01 & 0.0003 & 0.7580 & 0.0099 \\
\hline & Pine ${ }^{(5)}$ & $6.79^{\mathrm{a}}$ & $6.80^{\mathrm{a}}$ & $6.69^{\mathrm{b}}$ & $6.82^{\mathrm{a}}$ & 0.02 & 0.0055 & 0.7644 & 0.0338 \\
\hline \multirow{2}{*}{24} & Herb & 6.24 & 6.53 & 6.49 & 6.51 & 0.11 & 0.2922 & 0.1268 & 0.3111 \\
\hline & Pine & $6.70^{\mathrm{a}}$ & $6.73^{\mathrm{a}}$ & $6.56^{\mathrm{b}}$ & $6.71^{\mathrm{a}}$ & 0.03 & 0.0136 & 0.2929 & 0.2027 \\
\hline \multicolumn{10}{|c|}{ Microbial growth rate, OD at $550 \mathrm{~nm}$} \\
\hline \multirow{2}{*}{12} & Herb & $0.42^{\mathrm{a}}$ & $0.30^{\mathrm{b}}$ & $0.41^{\mathrm{a}}$ & $0.39 \mathrm{ab}$ & 0.03 & 0.0792 & 0.7914 & 0.0901 \\
\hline & Pine & 0.34 & 0.34 & 0.40 & 0.35 & 0.06 & 0.8686 & 0.7922 & 0.7290 \\
\hline \multirow{2}{*}{24} & Herb & $0.35^{\mathrm{ab}}$ & $0.37 \mathrm{ab}$ & $0.37^{\mathrm{a}}$ & $0.31^{b}$ & 0.02 & 0.1179 & 0.2543 & 0.0433 \\
\hline & Pine & 0.35 & 0.29 & 0.38 & 0.35 & 0.03 & 0.1862 & 0.5431 & 0.3383 \\
\hline \multicolumn{10}{|c|}{ Glucose $\left(\mathrm{mg} \cdot \mathrm{mL}^{-1}\right)$} \\
\hline \multirow{2}{*}{12} & Herb & $0.07^{\mathrm{a}}$ & $0.06^{\mathrm{bc}}$ & $0.06^{\mathrm{c}}$ & $0.07^{\mathrm{ab}}$ & 0.00 & 0.0244 & 0.1329 & 0.0086 \\
\hline & Pine & 0.06 & 0.08 & 0.06 & 0.05 & 0.01 & 0.2376 & 0.1892 & 0.1667 \\
\hline \multirow{2}{*}{24} & Herb & $0.05^{\mathrm{b}}$ & $0.07^{\mathrm{a}}$ & $0.05^{\mathrm{b}}$ & $0.06^{\mathrm{ab}}$ & 0.01 & 0.0242 & 0.2306 & 0.0446 \\
\hline & Pine & 0.06 & 0.06 & 0.05 & 0.05 & 0.01 & 0.3502 & 0.1135 & 0.4862 \\
\hline \multicolumn{10}{|c|}{ Protein $\left(\mathrm{mg} \cdot \mathrm{mL}^{-1}\right)$} \\
\hline \multirow{2}{*}{12} & Herb & $0.20^{\mathrm{a}}$ & $0.17^{\mathrm{ab}}$ & $0.18^{a b}$ & $0.16^{\mathrm{b}}$ & 0.01 & 0.0962 & 0.0273 & 0.8446 \\
\hline & Pine & 0.20 & 0.20 & 0.23 & 0.21 & 0.01 & 0.1537 & 0.2807 & 0.4698 \\
\hline \multirow{2}{*}{24} & Herb & $0.19^{\mathrm{b}}$ & $0.19^{\mathrm{b}}$ & $0.20^{\mathrm{ab}}$ & $0.21^{\mathrm{a}}$ & 0.01 & 0.0473 & 0.0105 & 0.2879 \\
\hline & Pine & 0.22 & 0.22 & 0.23 & 0.21 & 0.01 & 0.3240 & 0.7081 & 0.1946 \\
\hline \multicolumn{10}{|c|}{ Ammonia nitrogen $\left(\mathrm{mg} \cdot \mathrm{mL}^{-1}\right)$} \\
\hline \multirow{2}{*}{12} & Herb & $3.18^{\mathrm{a}}$ & $3.93^{a}$ & $1.18^{\mathrm{b}}$ & $2.93^{\mathrm{a}}$ & 0.44 & 0.0123 & 0.1272 & 0.6570 \\
\hline & Pine & 3.98 & 7.78 & 4.16 & 6.33 & 1.15 & 0.1324 & 0.4231 & 0.3784 \\
\hline \multirow{2}{*}{24} & Herb & $2.60^{\mathrm{ab}}$ & $2.27^{b}$ & $4.31^{\mathrm{a}}$ & $2.89^{\mathrm{ab}}$ & 0.52 & 0.0983 & 0.2542 & 0.5618 \\
\hline & Pine & $4.80^{\mathrm{b}}$ & $4.78^{\mathrm{b}}$ & $5.51^{\mathrm{ab}}$ & $6.53^{\mathrm{a}}$ & 0.46 & 0.0854 & 0.0260 & 0.1910 \\
\hline
\end{tabular}

(1) Extract concentrations are based on quantity of Timothy Hay (300 mg) substrate. (2) SEM, Standard error of the mean. (3) T, Treatments effect; L, Linear effect; Q, Quadratic effect. (4) Herb: Mentha canadensis plant extract. (5) Pine: Pinus densiflora plant extract. ${ }^{\mathrm{a}-\mathrm{c}}$ Means with different superscript letters in the same row indicate significant differences $(p<0.05)$.

Table 3 shows the effects of different $P$. densiflora and $M$. canadensis extracts on dry matter (DM) degradability and their parameters after the different incubation periods. There was no significant difference across treatments, although there was a pattern of DM degradability with time.

\subsection{Effect of Terpene-Based Plant Extracts on Gas Profiles}

Except for the $50 \mathrm{mg} / \mathrm{L}$ additive, $M$. canadensis extracts had a significantly higher effect on cumulative gas production (treatments effect, $p=0.0011$ ). Methane emission was significantly higher $(p<0.05)$ at $50 \mathrm{mg} / \mathrm{L}$ of $M$. canadensis extract after $12 \mathrm{~h}$ of incubation (treatments effect, $p=0.0029$ ). Pinus densiflora extracts showed significantly lower methane emission than the control, at $30 \mathrm{mg} / \mathrm{L}$ and $50 \mathrm{mg} / \mathrm{L}$ doses, after $12 \mathrm{~h}$ of incubation (treatments effect, $p=0.0024$; linear effect, $p=0.0048$ ). Carbon dioxide emission was higher in the $50 \mathrm{mg} / \mathrm{L}$ treatments than in the rest at $12 \mathrm{~h}$ (Table 4; herb: treatments effect, $p=0.0012$, quadratic effect, $p=0.0116$; pine: treatments effect, $p=0.0047$; quadratic effect, $p=0.0553$ ). 
Table 3. Effects of terpene-based plant extracts on dry matter (DM) degradability after $72 \mathrm{~h}$ of in vitro incubation.

\begin{tabular}{|c|c|c|c|c|c|c|c|c|c|}
\hline \multirow{2}{*}{ Incubation Time (h) } & \multirow{2}{*}{ Treatment } & \multicolumn{4}{|c|}{ Extract Concentration $^{(1)}(\mathrm{mg} / \mathrm{L})$} & \multirow{2}{*}{ SEM $^{(2)}$} & \multicolumn{3}{|c|}{$p$ Value $^{(3)}$} \\
\hline & & 0 & 30 & 50 & 70 & & $T$ & $\mathbf{L}$ & $\mathbf{Q}$ \\
\hline \multicolumn{10}{|c|}{ DM degradability, \% } \\
\hline \multirow{2}{*}{3} & Herb ${ }^{(4)}$ & 19.33 & 18.67 & 17.89 & 19.56 & 0.76 & 0.4468 & 0.8850 & 0.1900 \\
\hline & Pine ${ }^{(5)}$ & 22.11 & 21.22 & 23.00 & 21.33 & 1.29 & 0.7519 & 0.9133 & 0.8601 \\
\hline \multirow{2}{*}{6} & Herb & 20.11 & 19.78 & 19.00 & 19.67 & 1.14 & 0.9159 & 0.6732 & 0.7375 \\
\hline & Pine & 23.00 & 22.00 & 23.11 & 22.22 & 0.82 & 0.7196 & 0.7093 & 0.8722 \\
\hline \multirow{2}{*}{9} & Herb & 21.44 & 21.22 & 21.22 & 20.00 & 1.01 & 0.7416 & 0.3842 & 0.5983 \\
\hline & Pine & 23.00 & 23.89 & 23.44 & 23.11 & 1.14 & 0.9444 & 0.9673 & 0.5882 \\
\hline \multirow{2}{*}{12} & Herb & 27.11 & 26.33 & 27.11 & 27.33 & 0.38 & 0.332 & 0.5261 & 0.1647 \\
\hline & Pine & 29.89 & 29.78 & 29.11 & 31.00 & 0.85 & 0.505 & 0.5529 & 0.2887 \\
\hline \multirow{2}{*}{24} & Herb & 30.78 & 33.78 & 34.67 & 29.44 & 2.00 & 0.2816 & 0.8716 & 0.0784 \\
\hline & Pine & 32.44 & 33.22 & 31.44 & 33.33 & 1.25 & 0.6992 & 0.8741 & 0.7543 \\
\hline \multirow{2}{*}{48} & Herb & 41.22 & 38.33 & 39.78 & 33.78 & 1.77 & 0.0776 & 0.0314 & 0.3655 \\
\hline & Pine & 36.89 & 37.67 & 39.11 & 36.56 & 0.97 & 0.3167 & 0.8298 & 0.1564 \\
\hline \multirow{2}{*}{72} & Herb & 49.37 & 52.46 & 50.79 & 50.96 & 1.43 & 0.5362 & 0.5485 & 0.3099 \\
\hline & Pine & 48.67 & 48.56 & 55.22 & 51.89 & 1.63 & 0.0594 & 0.0568 & 0.6463 \\
\hline
\end{tabular}

(1) Extract concentrations are based on quantity of Timothy Hay (300 mg) substrate. (2) SEM, Standard error of the mean. ${ }^{(3)}$ T, Treatments effect; L, Linear effect; Q, Quadratic effect. ${ }^{(4)}$ Herb: Mentha canadensis plant extract. ${ }^{(5)}$ Pine: Pinus densiflora plant extract.

Table 4. Effects of terpene-based plant extracts on gas profiles after 12 and $24 \mathrm{~h}$ of in vitro incubation.

\begin{tabular}{|c|c|c|c|c|c|c|c|c|c|}
\hline \multirow{2}{*}{ Incubation Time (h) } & \multirow{2}{*}{ Treatment } & \multicolumn{4}{|c|}{ Extract Concentration $^{(1)}(\mathrm{mg} / \mathrm{L})$} & \multirow{2}{*}{ SEM $^{(2)}$} & \multicolumn{3}{|c|}{$p$ Value ${ }^{(3)}$} \\
\hline & & 0 & 30 & 50 & 70 & & $\mathrm{~T}$ & L & $Q$ \\
\hline \multicolumn{10}{|c|}{ Total gas, mL/g DM } \\
\hline \multirow{2}{*}{12} & Herb ${ }^{(4)}$ & $190.27^{b}$ & $189.64^{\mathrm{b}}$ & $204.58^{a}$ & $187.32^{b}$ & 2.01 & 0.0011 & 0.4233 & 0.0094 \\
\hline & Pine ${ }^{(5)}$ & $167.94^{\mathrm{ab}}$ & $163.24^{b c}$ & $175.01^{\mathrm{a}}$ & $159.49^{c}$ & 2.37 & 0.0088 & 0.2539 & 0.0950 \\
\hline \multirow{2}{*}{24} & Herb & 212.13 & 207.75 & 214.03 & 205.00 & 4.75 & 0.5535 & 0.4962 & 0.6923 \\
\hline & Pine & $176.97^{b}$ & $177.92^{b}$ & $187.32^{\mathrm{a}}$ & $176.97^{b}$ & 2.79 & 0.0811 & 0.4221 & 0.1367 \\
\hline \multicolumn{10}{|c|}{ Methane, mL/g DM } \\
\hline \multirow{2}{*}{12} & Herb & $10.83^{b}$ & $9.40^{b}$ & $13.33^{\mathrm{a}}$ & $9.49^{b}$ & 0.54 & 0.0029 & 0.9572 & 0.1585 \\
\hline & Pine & $11.95^{\mathrm{a}}$ & $8.68^{b}$ & $11.13^{\mathrm{a}}$ & $8.36^{b}$ & 0.51 & 0.0024 & 0.0048 & 0.5125 \\
\hline \multirow{2}{*}{24} & Herb & 19.33 & 16.84 & 18.39 & 17.24 & 1.10 & 0.4242 & 0.3173 & 0.5270 \\
\hline & Pine & 17.22 & 12.90 & 19.83 & 11.30 & 3.23 & 0.2955 & 0.4683 & 0.6308 \\
\hline \multicolumn{10}{|c|}{ Carbon dioxide, $\mathrm{mL} / \mathrm{g}$ DM } \\
\hline \multirow{2}{*}{12} & Herb & $61.30^{b}$ & $64.26^{\mathrm{b}}$ & $88.00^{\mathrm{a}}$ & $64.66^{\mathrm{b}}$ & 3.20 & 0.0012 & 0.0348 & 0.0116 \\
\hline & Pine & $45.47^{\mathrm{b}}$ & $41.36^{\mathrm{bc}}$ & $52.44^{\mathrm{a}}$ & $37.38^{c}$ & 2.06 & 0.0047 & 0.2098 & 0.0553 \\
\hline \multirow{2}{*}{24} & Herb & 89.69 & 93.75 & 99.07 & 94.21 & 4.37 & 0.5405 & 0.3307 & 0.4248 \\
\hline & Pine & 56.73 & 50.79 & 57.75 & 48.01 & 4.72 & 0.4465 & 0.3809 & 0.7546 \\
\hline
\end{tabular}

(1) Extract concentrations are based on the quantity of Timothy Hay (300 mg) substrate. (2) SEM, Standard error of the mean. ${ }^{(3)}$ T, Treatments effect; L, Linear effect; Q, Quadratic effect. ${ }^{(4)}$ Herb: Mentha canadensis plant extract.

(5) Pine: Pinus densiflora plant extract. ${ }^{\mathrm{a}-\mathrm{c}}$ Means with different superscript letters in the same row indicate significant differences $(p<0.05)$.

\subsection{Effect of Terpene-Based Plant Extracts on VFA Profiles}

The total volatile fatty acid (VFA) concentration under the $50 \mathrm{mg} / \mathrm{L}$ M. canadensis treatment was significantly higher than that of the control after $12 \mathrm{~h}$ of incubation (treatments effect, $p<0.0001$; linear effect, $p=0.0001$; quadratic effect, $p<0.0001$ ). Acetate concentration after treatment with $50 \mathrm{mg} / \mathrm{L}$ 
M. canadensis extract was also significantly higher at $12 \mathrm{~h}$ of incubation (treatments effect, $p<0.0001$; linear effect, $p=0.0019$; quadratic effect, $p=0.0004$ ).

The propionate concentration of $M$. canadensis extract $(50 \mathrm{mg} / \mathrm{L})$ was higher than in other treatments (treatments effect, $p=0.0003$; quadratic effect, $p=0.0015$ ). The methane concentration under $P$. densiflora extract treatments $(30$ and $50 \mathrm{mg} / \mathrm{L}$ ) was significantly lower than that under the control after $12 \mathrm{~h}$ of incubation (Table 5; treatments effect, $p=0.0049$; linear effect, $p=0.0009$ ).

Table 5. Effects of terpene-based plant extract on VFA profiles after 12 and $24 \mathrm{~h}$ of in vitro incubation.

\begin{tabular}{|c|c|c|c|c|c|c|c|c|c|}
\hline \multirow{2}{*}{ Incubation Time (h) } & \multirow{2}{*}{ Treatment } & \multicolumn{4}{|c|}{ Extract Concentration ${ }^{(1)}(\mathrm{mg} / \mathrm{L})$} & \multirow{2}{*}{ SEM $^{(2)}$} & \multicolumn{3}{|c|}{$p$ Value ${ }^{(3)}$} \\
\hline & & 0 & 30 & 50 & 70 & & $\mathrm{~T}$ & $\mathbf{L}$ & $\mathbf{Q}$ \\
\hline \multicolumn{10}{|c|}{ Total VFA, mM } \\
\hline \multirow{2}{*}{12} & Herb $^{(4)}$ & $53.85^{c}$ & $54.74^{\mathrm{b}}$ & $59.77^{\text {a }}$ & $54.79^{b}$ & 0.27 & $<0.0001$ & 0.0001 & $<0.0001$ \\
\hline & Pine ${ }^{(5)}$ & 53.98 & 60.36 & 59.37 & 55.70 & 1.95 & 0.1458 & 0.4766 & 0.0339 \\
\hline \multirow{2}{*}{24} & Herb & 62.40 & 63.15 & 65.17 & 62.46 & 1.50 & 0.5527 & 0.6974 & 0.3463 \\
\hline & Pine & 61.52 & 60.88 & 64.91 & 62.49 & 1.22 & 0.1815 & 0.2500 & 0.7364 \\
\hline \multicolumn{10}{|c|}{ Acetate, $\mathrm{mM}$} \\
\hline \multirow{2}{*}{12} & Herb & $36.58^{b}$ & $36.90^{\mathrm{b}}$ & $40.80^{\mathrm{a}}$ & $37.04^{\mathrm{b}}$ & 0.28 & $<0.0001$ & 0.0019 & 0.0004 \\
\hline & Pine & 36.20 & 39.68 & 39.22 & 36.40 & 1.79 & 0.4255 & 0.8482 & 0.1172 \\
\hline \multirow{2}{*}{24} & Herb & 42.62 & 42.91 & 44.49 & 42.60 & 0.91 & 0.4475 & 0.6737 & 0.3417 \\
\hline & Pine & 40.90 & 40.99 & 42.46 & 41.48 & 0.93 & 0.6371 & 0.4530 & 0.7138 \\
\hline \multicolumn{10}{|c|}{ Propionate, $\mathrm{mM}$} \\
\hline \multirow{2}{*}{12} & Herb & $10.56^{\mathrm{b}}$ & $10.77^{\mathrm{b}}$ & $11.88^{\mathrm{a}}$ & $10.61^{\mathrm{b}}$ & 0.13 & 0.0003 & 0.0367 & 0.0015 \\
\hline & Pine & $10.93^{b}$ & $11.74^{\mathrm{a}}$ & $11.92^{\mathrm{a}}$ & $10.92^{b}$ & 0.17 & 0.0049 & 0.5144 & 0.0009 \\
\hline \multirow{2}{*}{24} & Herb & 12.59 & 12.64 & 13.28 & 12.47 & 0.36 & 0.4306 & 0.8262 & 0.3357 \\
\hline & Pine & $12.52^{b}$ & $12.04^{b}$ & $13.44^{\mathrm{a}}$ & $12.17^{\mathrm{b}}$ & 0.28 & 0.0269 & 0.7993 & 0.3740 \\
\hline \multicolumn{10}{|c|}{ Butyrate, mM } \\
\hline \multirow{2}{*}{12} & Herb & 6.71 & 7.07 & 7.09 & 7.14 & 0.21 & 0.4762 & 0.1712 & 0.5345 \\
\hline & Pine & 6.84 & 8.94 & 8.23 & 8.38 & 0.48 & 0.0750 & 0.0744 & 0.0800 \\
\hline \multirow{2}{*}{24} & Herb & $7.20^{\mathrm{b}}$ & $7.59^{\mathrm{a}}$ & $7.41^{a b}$ & $7.40^{\mathrm{ab}}$ & 0.24 & 0.7228 & 0.6249 & 0.4097 \\
\hline & Pine & 8.11 & 7.85 & 9.01 & 8.84 & 0.36 & 0.1424 & 0.0828 & 0.6160 \\
\hline
\end{tabular}

(1) Extract concentrations are based on the quantity of Timothy Hay (300 mg) substrate. ${ }^{(2)}$ SEM, Standard error of the mean. ${ }^{(3)}$ T, Treatments effect; L, Linear effect; $Q$, Quadratic effect. ${ }^{(4)}$ Herb: Mentha canadensis plant extract. ${ }^{(5)}$ Pine: Pinus densiflora plant extract. ${ }^{\text {a-c }}$ Means with different superscript letters in the same row indicate significant differences $(p<0.05)$.

\subsection{Relative Quantification of Specific Ruminal Microbes}

Pinus densiflora extract, when added at $50 \mathrm{mg} / \mathrm{L}$, remarkably reduced Fibrobacter succinogenes compared to the other treatments at 12 and $24 \mathrm{~h}(12 \mathrm{~h}$ : treatment effect, $p=0.0010$, quadratic effect, $p=0.0025 ; 24 \mathrm{~h}$ : treatment effect, $p=0.0020$, quadratic effect, $p=0.0085)$. However, ciliate-associated methanogen increased at $12 \mathrm{~h}$ (treatment effect, $p=0.0165$; linear effect, $p=0.0155$ ). The proportion of Ruminococcus flavefaciens was significantly higher $(p<0.05)$ under P. densiflora extract treatment ( $50 \mathrm{mg} / \mathrm{L}$ addition) than under other treatments at $24 \mathrm{~h}$ of incubation (Figure 1 and Table 6).

Mentha canadensis extracts (50 mg/L treatments) also reduced F. succinogenes compared to other treatments at $12 \mathrm{~h}$ (treatment effect, $p=0.0001$; linear effect, $p=0.0061$; quadratic effect, $p=0.0004$ ), although ciliate-associated methanogen increased at $12 \mathrm{~h}$ (treatment effect, $p=0.0008$; linear effect, $p=0.0083$; quadratic effect, $p=0.0192$ ). The proportion of $F$. succinogenes was significantly lower $(p<0.05)$ than that under other treatments at $24 \mathrm{~h}$ (treatments effect, $p=0.0003$; linear effect, $p=0.0003$ ) (Figure 2 and Table 6). 

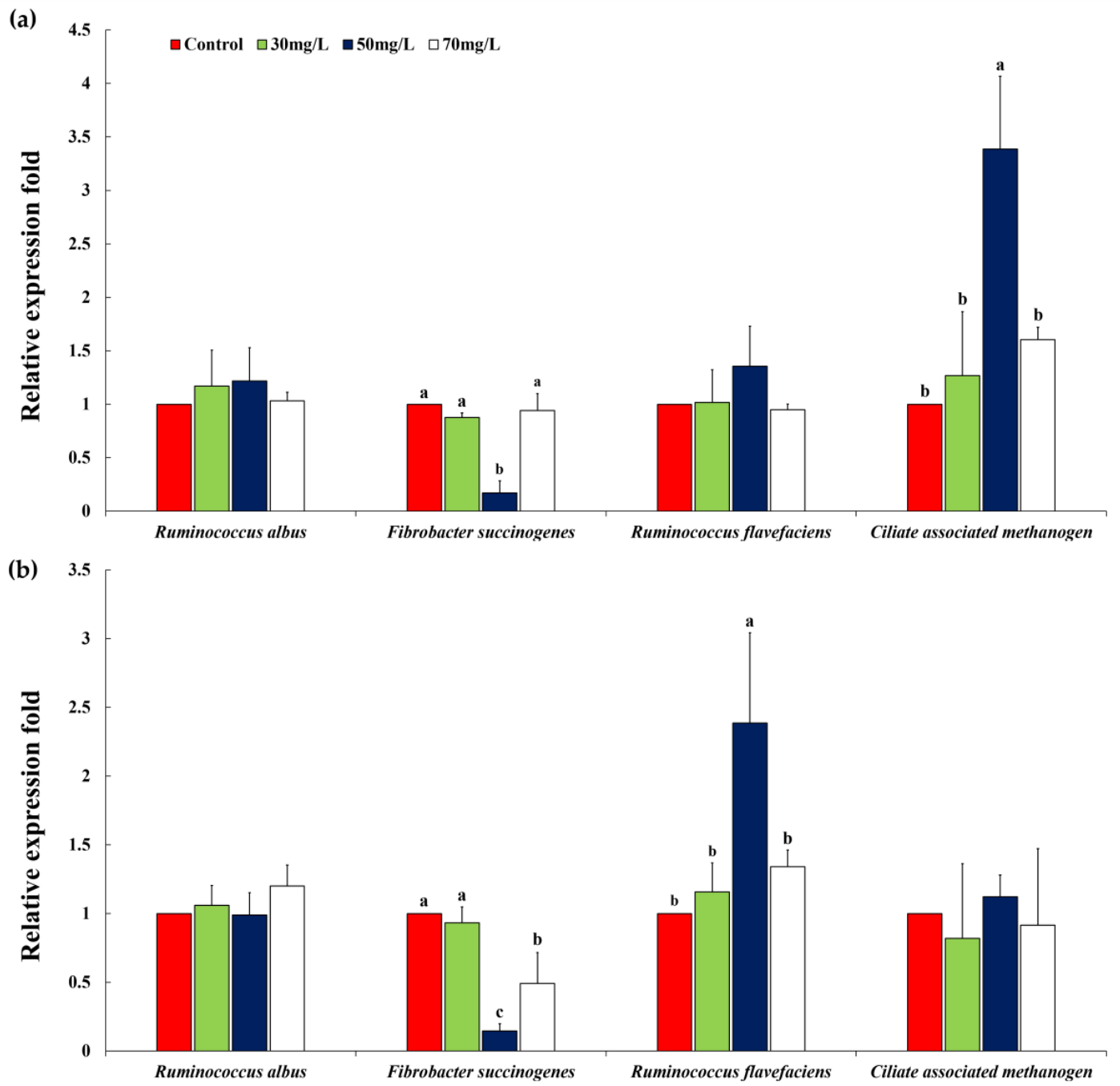

Figure 1. Relative quantification of in vitro rumen microbial population at (a) $12 \mathrm{~h}$ and (b) $24 \mathrm{~h}$ of incubation by Pinus densiflora. Error bars indicate the standard error of the mean $(n=3)$. ${ }^{\mathrm{a}-\mathrm{c}}$ Means with different superscript letters in the same row indicate significant differences $(p<0.05)$.

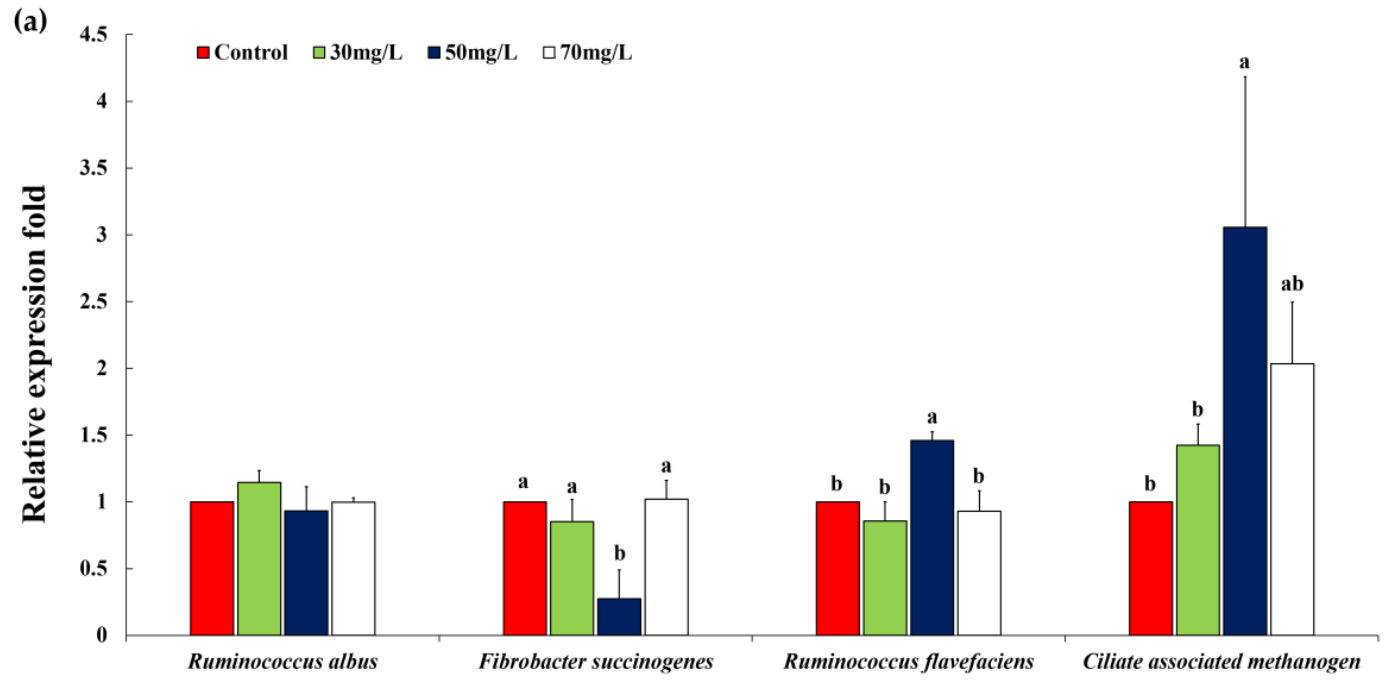

Figure 2. Cont. 


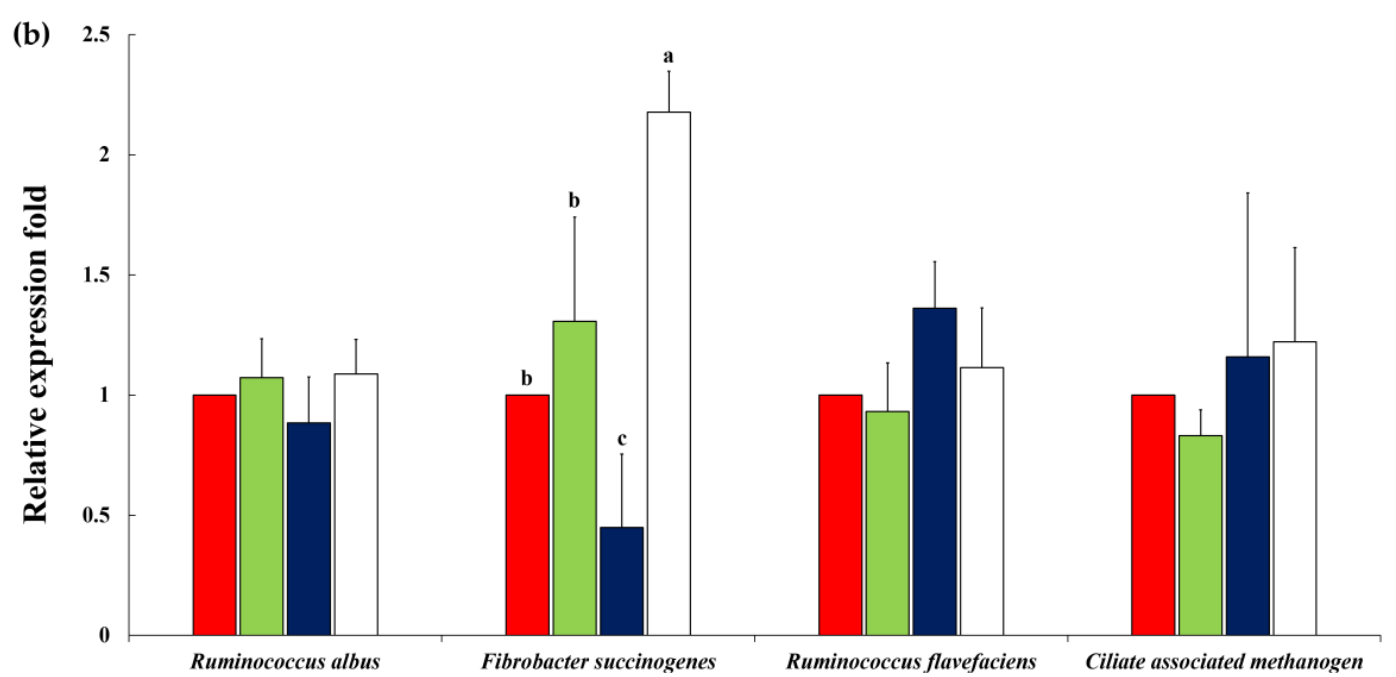

Figure 2. Relative quantification of in vitro rumen microbial population at (a) $12 \mathrm{~h}$ and (b) $24 \mathrm{~h}$ of incubation by Mentha canadensis. Error bars indicate the standard error of the mean $(n=3)$. ${ }^{\mathrm{a}-\mathrm{c}}$ Means with different superscript letters in the same row indicate significant differences $(p<0.05)$.

Table 6. Effect of Pinus densiflora and Mentha canadensis on abundances of bacteria, archaea and protozoa, in 12 and $24 \mathrm{~h}$ of in vitro incubation.

\begin{tabular}{|c|c|c|c|c|c|c|c|c|}
\hline \multirow{2}{*}{ Item } & \multicolumn{4}{|c|}{ Extract Concentration $^{(1)}(\mathrm{mg} / \mathrm{L})$} & \multirow{2}{*}{ SEM $^{(2)}$} & \multicolumn{3}{|c|}{$p$ Value $^{(3)}$} \\
\hline & 0 & 30 & 50 & 70 & & $\mathbf{T}$ & $\mathbf{L}$ & $Q$ \\
\hline \multicolumn{9}{|l|}{ Pinus densiflora $(12 h)$} \\
\hline Ruminococcus albus & 1.00 & 1.15 & 0.93 & 1.00 & 0.07 & 0.1930 & 0.5809 & 0.3892 \\
\hline Fibrobacter succinogenes & $1.00^{\mathrm{a}}$ & $0.85^{a}$ & $0.27^{\mathrm{b}}$ & $1.02^{\mathrm{a}}$ & 0.09 & 0.0010 & 0.1474 & 0.0025 \\
\hline Ruminococcus flavefaciens & $1.00^{\mathrm{b}}$ & $0.86^{\mathrm{b}}$ & $1.46^{\mathrm{a}}$ & $0.93^{b}$ & 0.07 & 0.0032 & 0.2266 & 0.0945 \\
\hline Ciliate associated methanogen & $1.00^{b}$ & $1.42^{b}$ & $3.06^{\mathrm{a}}$ & $2.03^{\mathrm{ab}}$ & 0.35 & 0.0165 & 0.0155 & 0.1927 \\
\hline \multicolumn{9}{|l|}{ Pinus densiflora $(24 h)$} \\
\hline Ruminococcus albus & 1.00 & 1.07 & 0.88 & 1.09 & 0.09 & 0.3989 & 0.8606 & 0.5979 \\
\hline Fibrobacter succinogenes & $1.00^{\mathrm{b}}$ & $1.31^{\mathrm{b}}$ & $0.45^{c}$ & $2.18^{\mathrm{a}}$ & 0.17 & 0.0020 & 0.0143 & 0.0085 \\
\hline Ruminococcus flavefaciens & 1.00 & 0.93 & 1.36 & 1.11 & 0.11 & 0.1553 & 0.1643 & 0.7306 \\
\hline Ciliate associated methanogen & 1.00 & 0.83 & 1.16 & 1.22 & 0.23 & 0.6440 & 0.4032 & 0.5144 \\
\hline \multicolumn{9}{|l|}{ Mentha Canadensis (12 h) } \\
\hline Ruminococcus albus & 1.00 & 1.17 & 1.22 & 1.03 & 0.13 & 0.6194 & 0.7263 & 0.2397 \\
\hline Fibrobacter succinogenes & $1.00^{\mathrm{a}}$ & $0.88^{a}$ & $0.17^{\mathrm{b}}$ & $0.94^{\mathrm{a}}$ & 0.06 & 0.0001 & 0.0061 & 0.0004 \\
\hline Ruminococcus flavefaciens & 1.00 & 1.02 & 1.35 & 0.95 & 0.14 & 0.2357 & 0.7238 & 0.2457 \\
\hline Ciliate associated methanogen & $1.00^{\mathrm{b}}$ & $1.27^{\mathrm{b}}$ & $3.39^{a}$ & $1.60^{\mathrm{b}}$ & 0.26 & 0.0008 & 0.0083 & 0.0192 \\
\hline \multicolumn{9}{|l|}{ Mentha Canadensis (24 h) } \\
\hline Ruminococcus albus & 1.00 & 1.06 & 0.99 & 1.2 & 0.0766 & 0.2605 & 0.1699 & 0.3500 \\
\hline Fibrobacter succinogenes & $1.00^{\mathrm{a}}$ & $0.93^{\mathrm{a}}$ & $0.15^{c}$ & $0.49^{b}$ & 0.0691 & 0.0003 & 0.0003 & 0.2000 \\
\hline Ruminococcus flavefaciens & 1.00 & 1.16 & 2.39 & 1.34 & 0.202 & 0.0050 & 0.0313 & 0.0500 \\
\hline Ciliate associated methanogen & $1.00^{b}$ & $0.82^{b}$ & $1.12^{\mathrm{a}}$ & $0.92^{b}$ & 0.2288 & 0.8152 & 0.9909 & 0.9500 \\
\hline
\end{tabular}

(1) Extract concentrations are based on quantity of Timothy Hay (300 mg) substrate. (2) SEM, Standard error of the mean. ${ }^{(3)}$ T, Treatments effect; L, Linear effect; Q, Quadratic effect. ${ }^{a-c}$ Means with different superscript letters in the same row indicate significant differences $(p<0.05)$.

\section{Discussion}

Polyphenolic compounds are secondary metabolites that are extensively distributed throughout the plant kingdom [31]. Polyphenol is a generic term used to encompass aromatic compounds that contain a hydroxyl group. Most polyphenol compounds, such as those in plant cell walls, polysaccharides, and lignin, including hydroxycinnamic acid, consist of ester bonds, or they exist as polymers [31,32]. In addition, they exhibit antioxidant properties by donating hydrogen via a hydroxyl group and stabilizing the resonance of the phenolic ring structure [33]. Total polyphenols and flavonoids influence antioxidant radical scavenging activity and are positively correlated [34,35], 
and such radical scavenging is generally determined using the DPPH radical and ABTS radical cation scavenging assays $[18,19]$. In macrophages, the inflammatory mediator NO plays an important role in killing bacteria or eliminating tumors; however, excessive NO formation owing to pathological causes could act as oxidative stress, causing cell damage, inflammation, and cancer [36]. In order to eliminate this oxidative stress, antioxidant and anti-inflammatory agents are important. Results of this study showed higher effects by $P$. densiflora extract than $M$. canadensis extract, which could be a very important factor in determining feed concentration. The $\mathrm{pH}$ range of rumen suitable for the digestion of high-fiber feed is 6.0-6.8 [37], and in this regard, the rumen $\mathrm{pH}$ range recorded in the present study was deemed to be adequate.

An analysis of the general components of $P$. densiflora revealed the following: moisture content, $53.48 \pm 0.60 \%$; crude protein content, $5.57 \pm 0.86 \%$; crude fat content, $5.16 \pm 0.44 \%$; crude ash content, $1.19 \pm 0.20 \%$; and crude fiber content, $11.32 \pm 0.98 \%$ [38]. For M. canadensis, the water content was found to be $81.95 \pm 1.60 \%$, crude protein content $1.25 \pm 0.98 \%$, crude fat content $0.40 \pm 0.41 \%$, ash content $2.05 \pm 0.75 \%$, and crude fiber content $2.48 \pm 0.56 \%$ [39]. In this experiment, using a two extract from a raw material with a relatively high moisture content led to a composition that did not appear to be significantly affected by digestibility. There was, in fact, no significant difference in DM digestibility. This observation, despite the high content of the extract, will be an important finding in support of its use as an additive in economic terms. The total amount of gases, methane and carbon dioxide, was the highest when $50 \mathrm{mg} / \mathrm{L}$ extract was added. Increase in gas production is evidence of good fermentation. However, as the level of addition increased, the results were not proportional, perhaps because the added amount was beyond optimal or toxic.

Pine had not shown antibacterial activity in any of the strains studied, except for the weak antibacterial activity seen in the $2-\mathrm{mm}$ clear zone at $10 \%$ concentration in Pityrosporum ovale [12]. In the present study, P. densiflora did not show any significant antibacterial activity. F. succinogenes levels suggested antibacterial activity when $50 \mathrm{mg} / \mathrm{L}$ extract was added, although the effect was not significant for the remaining microorganisms. Methane was reduced over the 12-h incubation period, owing to which the ciliate-associated methanogen may have decreased. However, in this experiment, it tended to increase in proportion to the amount of extract added. In particular, when $50 \mathrm{mg} / \mathrm{L}$ extract was added, it tended to increase explosively. We speculate that the observed increase in gas production could be ascribed to the limited negative effect of secondary metabolites, particularly flavonoids, in the extracts studied. These metabolites may have a positive influence on rumen fermentation, owing to their low to moderate amounts [40], or to the ability of rumen microorganisms to utilize these compounds as an energy source [41].

Microbial growth was significantly lower at $12 \mathrm{~h}$ in the case of $30 \mathrm{mg} / \mathrm{L}$ M. canadensis supplement. After $24 \mathrm{~h}$ of fermentation, it was significantly lower in the $70 \mathrm{mg} / \mathrm{L}$ supplementation group. Based on this, the optimal amount for the most effective microorganisms was identified as $50 \mathrm{mg} / \mathrm{L}$. As in the PCR results described above, the number of microorganisms observed in $50 \mathrm{mg} / \mathrm{L}$ addition was high.

Oskoueian [42] previously reported that methane production, rumen protozoa, and methanogen populations reduced when $4.5 \%$ naringin and quercetin were added. Flavonoids significantly reduced methane concentration $(p<0.05)$, and total gas production was significantly reduced by flavones, myristin and kaempferol $(p<0.05)$. Rutin, naringin, and quercetin significantly increased total gas production $(p<0.05)$. Therefore, flavonoids have sufficient potential as additives [42]. In this experiment, there was no significant difference in methane production during the $24 \mathrm{~h}$ fermentation, and the effect of methane reduction was seen over a $12 \mathrm{~h}$ period. Considering that we used an extract from a plant rather than a purified flavonoid, the persistence was not especially high. In addition, unlike the experiment by Oskoueian [42] using $45 \mathrm{mg} / \mathrm{L}$, methane emission showed a tendency to increase at $50 \mathrm{mg} / \mathrm{L}$ and decrease upon $30 \mathrm{mg} / \mathrm{L}$ and $70 \mathrm{mg} / \mathrm{L}$ additions. In in vitro batch culture for $12 \mathrm{~h}$, methane emission under the $30 \mathrm{mg} / \mathrm{L}$ M. canadensis (P. densiflora) treatment was $13 \%(27 \%)$ compared with that under the control, showing methane reduction. However, as reported in earlier studies, the reduction effect was not persistent. Oskoueian [42] reported gas production to significantly decrease 
by the use of kaempferol, flavone, and myricetin $(p<0.05)$, whereas it significantly increased by the use of quercetin, naringin, and rutin $(p<0.05)$. Flavonoids were also reported to significantly inhibit methane production $(p<0.05)$. Aderao [43] recommended Acacia nilotica and Ziziphus nummularia leaves, which are rich in polyphenols, to be used as a feed as they reduce methane and improve green livestock production. Akanmu et al. reported that the use of crude extract (Azadirachta indica, Moringa oleifera, Jatropha curcas, Tithonia diversifolia and Carica papaya) as feed decreased methane production and increased digestibility [44].

As mentioned above, most previous studies have suggested that the addition of flavonoids or terpenoids are effective in rumen fermentation and methane reduction; however, the concentration of each addition was not confirmed. Therefore, the analysis of appropriate levels, as demonstrated in the present study, is valuable. Lowry and Kennedy reported an increase in the concentration of acetate and butyrate upon fermentation of quercetin, rutin, and naringin by rumen microorganisms [45]. However, in this experiment, propionate increased only at $12 \mathrm{~h}$ after $50 \mathrm{mg} / \mathrm{L}$ of $P$. densiflora and M. canadensis extracts were added.

Based on methane production or antibacterial activity, the current study revealed the most appropriate level of supplementation to be $30 \mathrm{mg} / \mathrm{L}$. Many studies have been conducted on the ability to reduce methane, directly or indirectly, using flavonoids. Against Gram-positive bacteria, the production of propionate was increased compared to that of acetate in order to improve energy metabolism; such manipulation can contribute to increased efficiency of ruminant animals. This finding is similar to that of ionophores and represents antibacterial effects [45] Broudiscou et al. reported that Equisetum arvense extract and Salvia officinalis extract reduce methane by $1 \%-8 \%$ [46]. Another study using flavone, myricetin, and kaempferol demonstrated a reduced population of total bacteria, fungi, protozoa, and methanogens compared to that in control groups. Catechin reduced the total population of protozoan animals compared to that in the control group. Quercetin has been shown to reduce the total proportion of bacteria, fungi, protozoa, and methanogens in rumen [47].

Some flavonoids are effective in mitigating methane production and reducing acetate with propionates. However, the dose used in in-vitro experiments has been reported to be an additional dose that is not actually available in animal experiments and depends on the efficacy of a specific compound and response to its action [42]. Refined chemicals or synthetics would be more effective as feed for reducing methane; however, animals that have the feed would eventually be eaten by humans. Stability against chemicals has not yet been proven, and in-depth studies on relatively safer plant feed additives should be conducted in future. In conclusion, the effects of methane reduction and antioxidant properties could be confirmed by adding plant extracts containing phenol or flavonoids.

\section{Conclusions}

In this study, we confirmed the effects of plant extracts (derived from P. densiflora and M. canadensis) containing phenols and flavonoids on methane reduction and rumen fermentation. We found that the effects on methane emission were highest in those ruminants receiving P. densiflora and M. canadensis extracts at concentrations of 30 and $70 \mathrm{mg} / \mathrm{L}$. With respect to rumen fermentation with different digestibility rates, we detected no difference between the effect of extracts supplemented at these two concentrations. Consequently, from an economic point of view, supplementing diets with a $30 \mathrm{mg} / \mathrm{L}$ extract would be considered the most beneficial. However, it is well established that additives and antibiotics of natural origin are more beneficial to animals than are their synthetic counterparts. Therefore, although the process is complex and time consuming, further research in this direction is warranted.

Author Contributions: Conceptualization, S.J.L., Y.J.L. and S.S.L.; methodology Y.J.L., S.N.K.; software, Y.Y.C.; validation, H.S.K.; Y.J.L. and J.S.E.; writing-original draft preparation, S.J.L. and S.U.J.; writing-review and editing, H.Y.P., D.H.K., S.J.L. and S.S.L.; visualization, S.J.L.; supervision, S.J.L.; project administration, S.S.L.; funding acquisition, S.S.L. All authors have read and agreed to the published version of the manuscript. 
Funding: Support for this research was provided by the National Research Foundation of Korea, grant number NRF-2015R1A6A1A03031413.

Conflicts of Interest: The authors declare no conflict of interest.

\section{References}

1. Moss, A.R.; Jouany, J.P.; Newbold, J. Methane production by ruminants: Its contribution to global warming. Ann. Zootech. 2000, 49, 231-253. [CrossRef]

2. Calabrò, S.; Infascelli, F.; Tudisco, R.; Musco, N.; Grossi, M.; Monastra, G.; Cutrignelli, M.I. Estimation of in vitro methane production in buffalo and cow. Buffalo Bull. 2013, 32, 924-927. Available online: https://www.researchgate.net/publication/282576097 (accessed on 10 April 2013).

3. Cummings, J.H.; Macfarlane, G.T. Gastrointestinal effects of prebiotics. Br. J. Nutr. 2002, 87, S145-S151. [CrossRef] [PubMed]

4. $\quad$ Ding, Y.Y.; Zhang, C.H.; He, X.L.; Huang, L.; Yin, Z.J. Growth performance responses and indicators of gastrointestinal health in early weaned pigs fed Chinese herbal medicine additives-supplemented diets. J. Anim. Vet. Adv. 2011, 10, 1580-1587. [CrossRef]

5. Kwak, C.S.; Moon, S.C.; Lee, M.S. Antioxidant, antimutagenic, and antitumor effects of pine needles (Pinus densiflora). Nutr. Cancer 2006, 56, 162-171. [CrossRef] [PubMed]

6. Won, S.B.; Jung, G.Y.; Kim, J.; Chung, Y.S.; Hong, E.K.; Kwon, Y.H. Protective effect of Pinus koraiensis needle water extract against oxidative stress in HepG2 cells and obese mice. J. Med. Food 2013, 16, 569-576. [CrossRef] [PubMed]

7. Hwang, Y.J.; Wi, H.R.; Kim, H.R.; Park, K.W.; Hwang, K.A. Pinus densiflora Sieb. et Zucc. alleviates lipogenesis and oxidative stress during oleic acid-induced steatosis in HepG2 cells. Nutrients 2014, 6, 2956-2972. [CrossRef]

8. Lee, J.S.; Kim, H.G.; Lee, H.W.; Kim, W.Y.; Ahn, Y.C.; Son, C.G. Pine needle extract prevents hippocampal memory impairment in acute restraint stress mouse model. J. Ethnopharmacol. 2017, 207, 226-236. [CrossRef]

9. Koukos, P.K.; Papadopoulou, K.I.; Patiaka, D.T.; Papagiannopoulos, A.D. Chemical composition of essential oils from needles and twigs of balkan pine (Pinus peuce Grisebach) grown in Northern Greece. J. Agric. Food Chem. 2000, 48, 1266-1268. [CrossRef]

10. Kim, Y.J.; Cho, B.J.; Ko, M.S.; Jung, M.J.; Kim, H.R.; Song, H.S.; Lee, J.Y.; Sim, S.S.; Kim, S.J. Anti-oxidant and Anti-aging Activities of Essential Oils of Pinus densiflora Needles and Twigs. Pharm. Soc. Korea 2010, 54, 215-225.

11. Hong, E.J.; Na, K.J.; Choi, I.G.; Choi, K.C.; Jeung, E.B. Antibacterial and Antifungal Effects of Essential Oils from Coniferous Trees. Biol. Pharm. Bull. 2004, 27, 863-866. [CrossRef] [PubMed]

12. Shin, Y.H.; Kim, H.J.; Lee, J.Y.; Cho, Y.J.; An, B.J. Major Compound Analysis and Assessment of Natural Essential Oil on Anti-Oxidative and Anti-Microbial Effects. J. Life Sci. 2012, 22, 1344-1351. [CrossRef]

13. Brahmi, F.; Khodir, M.; Mohamed, C.; Pierre, D. Chemical composition and biological activities of Mentha species. Aromat. Med. Plants-Back Nat. 2017, 47-78. [CrossRef]

14. Snoussi, M.; Noumi, E.; Trabelsi, N.; Flamini, G.; Papetti, A.; Feo, V.D. Mentha spicata Essential Oil: Chemical Composition, Antioxidant and Antibacterial Activities against Planktonic and Biofilm Cultures of Vibrio spp. Strains. Molecules 2015, 20, 4402-4424. [CrossRef]

15. Kim, D.H.; Lee, S.J.; Oh, D.S.; Lee, I.D.; Eom, J.S.; Park, H.Y.; Choi, S.H.; Lee, S.S. In vitro evaluation of Rhus succedanea extracts for ruminants. Asian-Australas. J. Anim. Sci. 2018, 31, 1635-1642. [CrossRef]

16. McDougall, E.I. Studies on ruminant saliva. 1. The composition and output of sheep's saliva. Biochem. J. 1948, 43, 99-109. [CrossRef]

17. Singleton, V.L.; Rossi, J.R. Colorimetry of total phenolics with phosphomolybdic-phosphotungstic acid reagents. Am. J. Enol. Vitic. 1965, 16, 144-158.

18. Meda, A.; Lamien, C.E.; Romito, M.; Millogo, J.; Nacoulma, O.G. Determination of the total phenolic, flavonoid and proline contents in Burkina Fasan honey, as well as their radical scavenging activity. Food Chem. 2005, 91, 571-577. [CrossRef]

19. Kang, S.N.; Semeneh, S.; Lee, J.S.; Lee, S.; Lee, H.J.; Kim, G.R.; Yeo, J.H.; Kim, J.Y. Evaluation of Antioxidant and Antimicrobial Activities of Ethanol Extracts of Three Kinds of Strawberries. Prev. Nutr. Food Sci. 2017, 22, 203-210. [CrossRef] 
20. Brand-Williams, W.; Cuvelier, M.E.; Berset, C. Use of a free radical method to evaluate antioxidant activity. LWT Food Sci. Technol. 1995, 28, 25-30. [CrossRef]

21. Re, R.; Pellegrini, N.; Proteggente, A.; Pannala, A.; Yang, M.; Rice-Evans, C. Antioxidant activity applying an improved ABTS radical cation decolorization assay. Free Radic. Biol. Med. 1999, 26, 1231-1237. [CrossRef]

22. Elizabeth, K.; Rao, M.N.A. Oxygen radical scavenging activity of curcumin. Int. J. Pharm. 1990, 58, 237-240.

23. Lee, H.S. Antioxidative activity of browning reaction products isolated from storage-aged orange juice. J. Agric. Food Chem. 1992, 40, 550-552. [CrossRef]

24. Lee, S.J.; Jeong, J.S.; Shin, N.H.; Lee, S.K.; Kim, H.S.; Eom, J.S.; Lee, S.S. Impact of Ecklonia stolonifera extract on in vitro ruminal fermentation characteristics, methanogenesis, and microbial populations. Asian Australas. J. Anim. Sci. 2019, 32, 1864-1872. [CrossRef]

25. Lee, S.J.; Shin, N.H.; Jeong, J.S.; Kim, E.T.; Lee, S.K.; Lee, I.D.; Lee, S.S. Effects of Gelidium amansii extracts on in vitro ruminal fermentation characteristics, methanogenesis, and microbial populations. Asian Australas. J. Anim. Sci. 2018, 31, 71-79. [CrossRef]

26. Denman, S.E.; McSweeney, C.S. Development of a real-time PCR assay for monitoring anaerobic fungal and cellulolytic bacterial populations within the rumen. FEMS Microbiol. Ecol. 2006, 58, 572-582. [CrossRef]

27. Koike, S.; Kobayashi, Y. Development and use of competitive PCR assays for the rumen cellulolytic bacteria: Fibrobacter succinogenes, Ruminococcus albus and Ruminococcus flavefaciens. FEMS Microbiol. Lett. 2001, 204, 361-366. [CrossRef]

28. Skillman, L.C.; Toovey, A.F.; Williams, A.J.; Wright, A.D.G. Development and validation of a real-time PCR method to quantify rumen protozoa and examination of variability between Entodinium populations in sheep offered a hay-based diet. Appl. Environ. Microb. 2006, 72, 200-2006. [CrossRef]

29. Luton, P.E.; Wayne, J.M.; Sharp, R.J.; Riley, P.W. The mcrA gene as an alternative to $16 \mathrm{~S}$ rRNA in the phylogenetic analysis of methanogen populations in landfill. Microbiology 2002, 148, 3521-3530. [CrossRef]

30. SAS Institute Inc. SAS/STAT User's Guide: Version 9.2; SAS Institute Inc.: Cary, NC, USA, 2002.

31. Ignat, I.; Volf, I.; Popa, V.I. A critical review of methods for characterisation of polyphenolic compounds in fruits and vegetables. Food Chem. 2011, 126, 1821-1835. [CrossRef]

32. Arigò, A.; Česla, P.; Šilarová, P.; Calabrò, M.L.; Česlová, L. Development of extraction method for characterization of free and bonded polyphenols in barley (Hordeum vulgare L.) grown in Czech Republic using liquid chromatography-tandem mass spectrometry. Food Chem. 2018, 245, 829-837. [CrossRef] [PubMed]

33. Tsao, R.; Yang, R. Optimization of a new mobile phase to know the complex and real polyphenolic composition: Towards a total phenolic index using high-performance liquid chromatography. J. Chromatogr. A 2003, 1018, 29-40. [CrossRef] [PubMed]

34. Herrmann, K. Occurrence and content of hydroxycinnamic and hydroxy-benzoic acid compounds in foods. Crit. Rev. Food Sci. Nutr. 1989, 28, 315-347. [CrossRef]

35. Yusof, S.; Ghazali, H.M.; King, G.S. Naringin content in local citrus fruits. Food Chem. 1990, 37, $113-121$. [CrossRef]

36. McCartney-Francis, N.; Allen, J.B.; Mizel, D.E.; Albina, J.E.; Xie, Q.W.; Nathan, C.F.; Wahl, S.M. Supperession of arthritis by an inhibitor of nitric oxide synthase. J. Exp. Med. 1993, 178, 749-754. [CrossRef]

37. McCullough, M.E.; Smart, J.W.W.G. Effects of intake of forge level on ruminal turnover rate, bacterial protein synthesis and duodenal amino acid flow in sheep. J. Anim. Sci. 1968, 62, 216.

38. Lee, J.H.; Chung, H.S.; Kim, I.H.; Kim, S.H. Antioxidant Properties of Pinus koraiensis Needle Powder Extracts as Influenced by Drying Methods. Food Eng. Prog. 2013, 17, 396-400. [CrossRef]

39. Oh, M.H.; Whang, H.J. Chemical Composition of Several Herb Plants. Korean J. Food Sci. Technol. 2003, 35, 1-6.

40. Salem, A.Z.M.; Kholif, A.E.; Olivares, M.; Elghandour, M.M.; Mellado, M.; Arece, J. Influence of S. babylonica extract on feed intake, growth performance and diet in vitro gas production profile in young lambs. Trop. Anim. Health Prod. 2014, 46, 213-219. [CrossRef]

41. Boussaada, A.; Arhab, R.; Calabrò, S.; Grazioli, R.; Ferrara, M.; Musco, N.; Thlidjane, M.; Cutrignelli, M.I. Effect of Eucalyptus globulus leaves extracts on in vitro rumen fermentation, methanogenesis, degradability and protozoa population. Ann. Anim. Sci. 2018, 18, 753-767. [CrossRef]

42. Oskoueian, E.; Abdullah, N.; Oskoueian, A. Effects of flavonoids on rumen fermentation activity, methane production, and microbial population. BioMed Res. Int. 2013, 2013, 349129. [CrossRef] [PubMed] 
43. Aderao, G.N.; Sahoo, A.; Bhatt, R.S.; Kumawat, P.K.; Soni, L. In vitro rumen fermentation kinetics, metabolite production, methane and substrate degradability of polyphenol rich plant leaves and their component complete feed blocks. J. Anim. Sci. Technol. 2018, 60, 26. [CrossRef] [PubMed]

44. Akanmu, A.M.; Hassen, A.; Adejoro, F.A. Gas Production, Digestibility and Efficacy of Stored or Fresh Plant Extracts to Reduce Methane Production on Different Substrates. Animals 2020, 10, 146. [CrossRef] [PubMed]

45. Lowry, J.B.; Kennedy, P.M. Fermentation of flavonols by rumen organisms. Proc. Aust. Soc. Anim. Prod. 1996, $21,366$.

46. Olagaray, K.E.; Bradford, B.J. Plant flavonoids to improve productivity of ruminants. Anim. Feed Sci. Technol. 2019, 251, 21-36. [CrossRef]

47. Broudiscou, L.P.; Papon, Y.; Broudiscou, A.F. Effects of dry plant extracts on fermentation and methanogenesis in continuous culture of rumen microbes. Anim. Feed Sci. Technol. 2000, 87, 263-277. [CrossRef]

Publisher's Note: MDPI stays neutral with regard to jurisdictional claims in published maps and institutional affiliations.

(C) 2020 by the authors. Licensee MDPI, Basel, Switzerland. This article is an open access article distributed under the terms and conditions of the Creative Commons Attribution (CC BY) license (http://creativecommons.org/licenses/by/4.0/). 